\title{
Forecasting flood-prone areas using Shannon's entropy model
}

\author{
Ali Haghizadeh ${ }^{1, *}$, Safoura Siahkamari ${ }^{1}$, Amir Hamzeh Haghiabi ${ }^{2}$ and Omid Rahmati ${ }^{1}$ \\ ${ }^{1}$ Department of Watershed Management Engineering, Faculty of Agriculture, Lorestan University, Lorestan, Iran. \\ ${ }^{2}$ Department of Water Engineering, Faculty of Agriculture, Lorestan University, Lorestan, Iran. \\ *Corresponding author.e-mail: Haghizadeh.a@lu.ac.ir, alihaghi20@gmail.com
}

Withregard to the lack of quality information and data in watersheds, it is of high importance to present a new method for evaluating flood potential. Shannon's entropy model is a new model in evaluating dangers and it has not yet been used to evaluate flood potential. Therefore, being a new model in determining flood potential, it requires evaluation and investigation in different regions and this study is going to deal with this issue. For to this purpose, 70 flooding areas were recognized and their distribution map was provided by ArcGIS10.2 software in the study area. Information layers of altitude, slope angle, slope aspect, plan curvature, drainage density, distance from the river, topographic wetness index (TWI), lithology, soil type, and land use were recognized as factors affecting flooding and the mentioned maps were provided and digitized by GIS environment. Then, flood susceptibility forecasting map was provided and model accuracy evaluation was conducted using ROC curve and $30 \%$ flooding areas express good precision of the model $(73.5 \%)$ for the study area.

\section{Introduction}

Flood is defined as an increase in water level of rivers and floodways and flowing water along with covering plains around the river. Naturally, human activities have increased flood risk because of increasing population growth and rapid urban and rural development. Floods are regarded as the most dreadful climatic disaster in the world in terms of loss of life and property damage (Hosseini and Matlabifar 2008). Golestan province is among those regions of the country where short rain showers occur during warm seasons of the year and most of the time, these showers result in severe and devastating floods especially in the east area of this province that leaves huge property damage and life loss. Modelling flood in watersheds and reducing damages of these natural disasters is the primary objective of comprehensive management of watersheds (Rahmati et al. 2016a). Employing these methods accompanies difficulties because of limitations in different hydrologic methods to determine flood-prone areas and their need for large financial resources. Therefore, in many watersheds, authors employ environmental analyses in the form of GIS for hydrologic studies. Pourghasemi et al. (2014) conducted zoning of landslide susceptibility using Shannon's entropy index. Results of this study demonstrate that Shannon's entropy index with an accuracy of $82.83 \%$ is a very good index for zoning of landslide susceptibility for the study area. Hosseinpour and Abbaspour (2014) improved the results of forecasting landslide using Shannon's entropy theory. Results of their study showed that the cited model was $69 \%$ accurate in forecasting landslides. A similar study by Pourghasemi et al. (2012) was conducted to prepare landslide susceptibility mapping of Safarood watershed in

Keywords. Flood susceptibility; Shannon's entropy; Madarsoo; GIS. 
Ramsar using probability and Shannon's entropy models. Results of the models' evaluation suggest a high accuracy of entropy theory $(86.08 \%)$ relative to probability theory $(82.75 \%)$. Naghibi et al. (2014) employed Shannon's entropy and frequency ratio to prepare qanat potential mapping in the Moghan watershed. Results suggest that the area under the curve (AUC) for frequency ratio and Shannon's entropy models is 88.48 and $91.21 \%$, respectively. Bednarik et al. (2010) employed entropy index to assess landscape susceptibility of Slovakia and their results express good precision of model (70\%) using ROC curve. Jaafari et al. (2013) utilized frequency ratio and Shannon's entropy to prepare zoning map of landslides in Caspian forests by ArcGIS software. Their results suggest that Shannon's entropy model, with an accuracy of $75.59 \%$, could be employed as a simple tool in evaluating landslide susceptibility compared to frequency ratio with an accuracy of $72.68 \%$. Lee et al. (2012) used the frequency ratio (FR) model for predicting the flooding susceptibility map using GIS, the results of their study are expected to be used in programmes to reduce the flood and its damage. Shafapour Tehrani et al. (2013) in Malaysia, in a study, applied an integration of frequency ratio, logistic regression and decision tree methods for determining flood susceptibility. Results of their study showed that the use of machine learning methods such as decision trees increases the accuracy of the given methods for mapping the flood potential. Rahmati et al. (2016c) zoned flooding using frequency ratio and control weight in the Golestan province, the results of their research indicated that the two mentioned models were relatively similar, acceptable, as well as useful for flood risk reduction strategies.

Literature review indicates that Shannon's entropy model has been used by various researchers for modelling and analysis in the fields of hydrology and water resources management. Mishra et al. (2009) used an entropy-based method to measure the spatio-temporal variability of a precipitation time series in the State of Texas, USA. Singh (1997) reviewed applications of entropy concept in hydrology and water resources management and discusses their strengths and limitations. Kawachi et al. (2001) investigated the capability of Shannon's entropy to quantitatively measure the uncertainty of the over-a-year rainfall apportionment and to construct an isoentropy map in Japan. Their results indicated that the isoentropy map would be useful in conjunction with an isohyetal map of the average annual rainfall. Mishra and Coulibaly (2010, 2014) and Li et al. (2012) discussed the applicability of the entropy theory for the evaluation of an optimal hydrometric network and to identify essential streamflow stations. Recently,
Rajsekhar et al. (2012) used an entropy-based method for drought characterization and identification of homogenous regions based on drought duration and severity. With regard to the lack of quality information and data in watersheds of the country, it is of high importance to present a new method for evaluating the potential of flood and flood-prone areas. Flood susceptibility is among those studies with a short history in the world and it is regarded as one of the newest studies in the field of floods. In addition, Shannon's entropy model is a new method in risk assessment and it has never been used before to assess the potential of flood elsewhere. Therefore, being a new model, it should be assessed and investigated in different regions of the country in terms of determining flood susceptibility and this study is conducted for this purpose.

\section{Materials and methods}

\subsection{Study area}

The study area is one of the eastern sub-basins of Gorgan Rood River called Madarsoo watershed located in the longitude of $55^{\circ} 21^{\prime}-56^{\circ} 28^{\prime} \mathrm{N}$ and latitude of $36^{\circ} 58^{\prime}-37^{\circ} 30^{\prime} \mathrm{E}$ (figure 1). With an area of $2310.27 \mathrm{~km}^{2}$, this watershed, which is located in three provinces of Golestan, Semnan and Khorasan, according to political divisions, is one of the most popular watersheds of Golestan province and is popular for its devastating floods.

\subsection{Effective parameters in flooding}

Various data are required as independent variables in flood risk assessment (Liu and De Smedt 2005). These variables are very effective in flood occurrence in a special area. On the other hand, if we employ all these parameters in the modelling process, the huge amount of information would prevent quick and extract analyses (Campolo et al. 2003; Sanyal and Lu 2004). No absolute guideline is defined yet. Some effective and finite parameters employed by authors to evaluate flood risk include: land use, lithology, soil type, drainage density, distance from river, topographic wetness index (TWI), altitude, slope aspect, slope angle and plan curvature (Skilodimou et al. 2003; Lee et al. 2012; Kia et al. 2012; Pradhan and Lee 2010; Shafapour et al. 2013, 2014).

\subsubsection{Altitude}

Different elevations change the climatic features and this issue results in changes in vegetation and soil conditions (Aniya 1985). Elevation always plays an important role in flood susceptibility maps (Rahmati et al. 2016b). Therefore, an elevation 


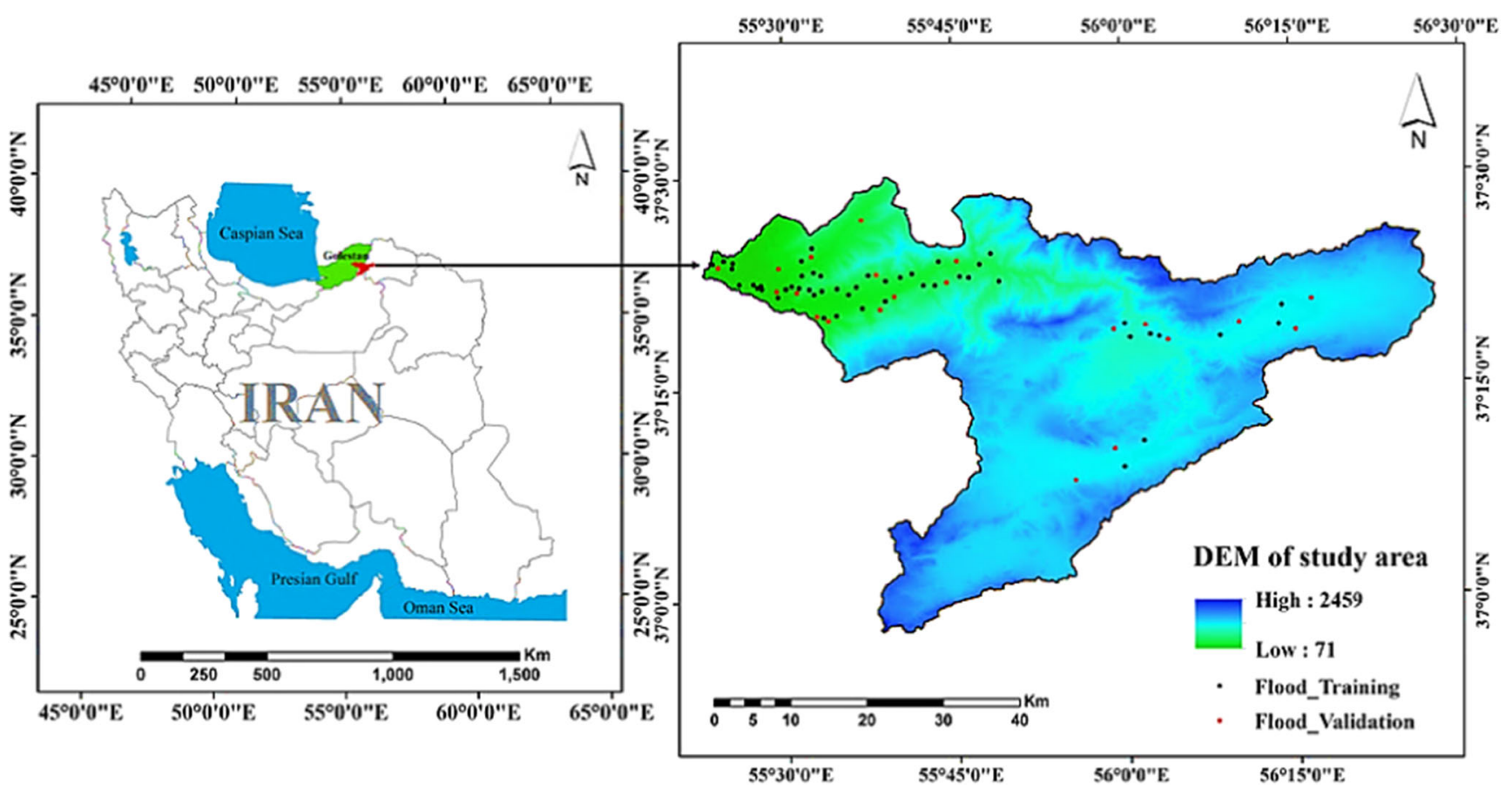

Figure 1. Geographical location of study area in Iran.
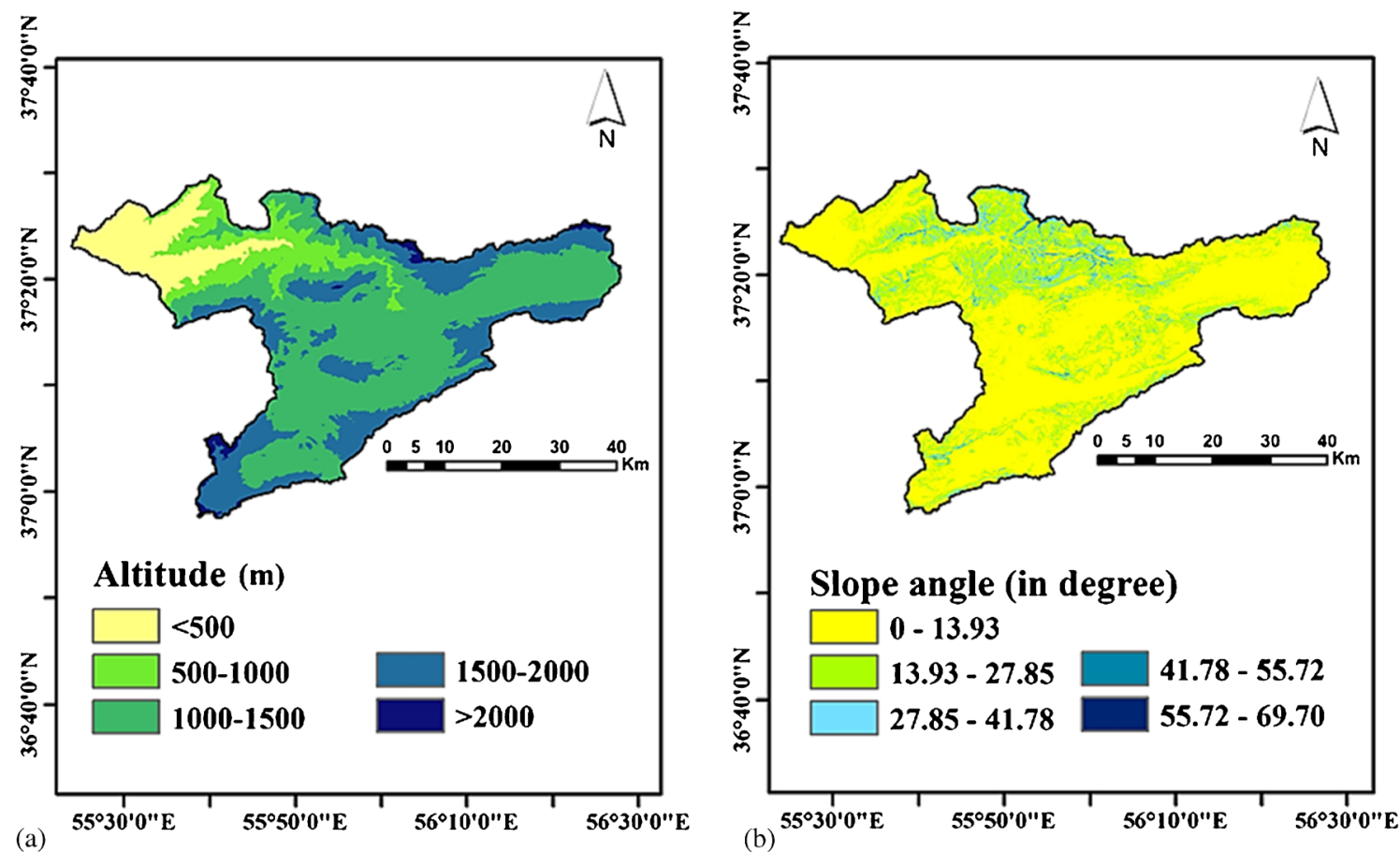

Figure 2. (a) Elevation map and (b) slope angle (in degree) in Madarsoo watershed.

map of the study area is provided from topographic maps and is divided into five categories using sequential classification method (figure 2a).

\subsubsection{Slope angle}

Because of having a direct effect on surface runoff and opportunities for permeation, the slope is regarded as a major factor in flood occurrence in watersheds. To prepare the map, digital elevation model (DEM) (with a resolution of $30 \mathrm{~m}$ ) was employed along with ArcGIS 10.2 software. The resulted map was classified into five classes of $0-13.93,13.93-27.85,27.85-41.78,41.78-55.72$ and 55.72-69.7 (in degrees). Figure 2(b) depicts classified slope map in the study watershed. 


\subsubsection{Slope aspect}

Slope aspect is an important factor in analyzing geomorphologic stability by controlling some climatic parameters including radiation received, wind (dry, wet), and intensity of precipitation and soil moisture. Determining the direction of water flow is one of the applications of the direction of slope map. Aspect map is drawn in ArcGIS 10.2 software using digital elevation map (DEM). This map is classified into nine groups, the levels of which are flat, north, north-east, east, south-east, south, south-west, west and north-west. Figure 3(a) depicts aspect map.

\subsubsection{Plan curvature}

Plan curvature is an effective factor on flood potential of watersheds. The curvature map is provided based on digital elevation model and ArcGIS 10.2. This map is categorized into three classes of concave curvature, convex curvature and flat (without curvature) (figure $3 \mathrm{~b}$ ).

\subsubsection{Drainage density}

Drainage density is the ratio of total length of watershed channels to the area of the basin. Waterways network in watershed shows the way water flows in the basin (Abdideh et al. 2011; Tahmassebipoor et al. 2016). Finally, drainage density map was classified into four groups using $30 \times 30 \mathrm{~m}$ cells (figure $4 \mathrm{a}$ ).

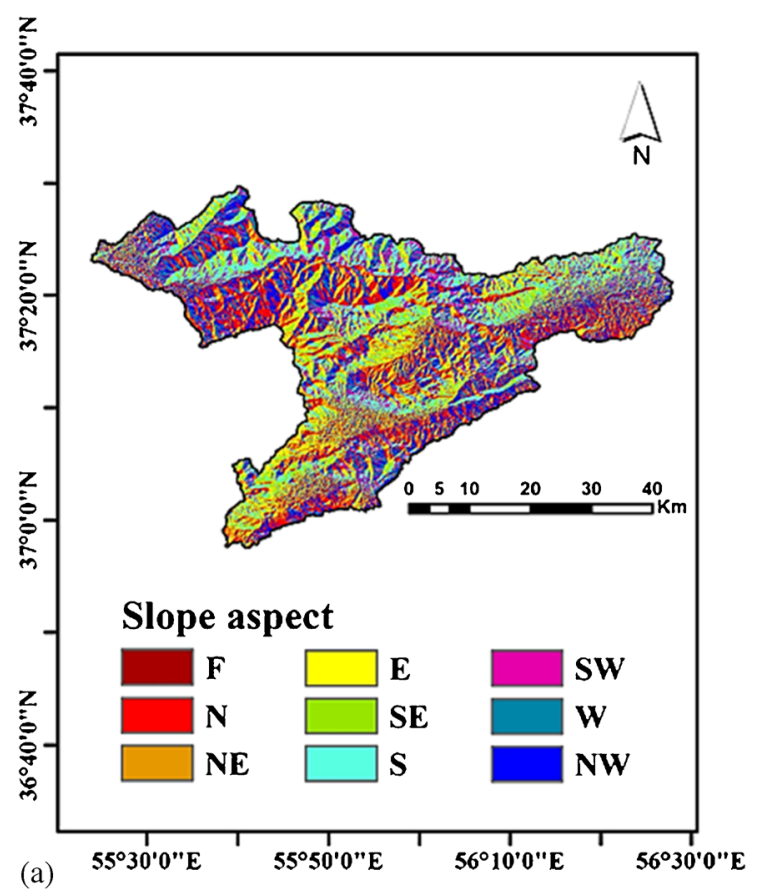

\subsubsection{Distance from river}

An important factor in flooding of adjacent lands is the distance from the river. Map of distance from the river was prepared based on a digital layer of flow network in ArcGIS 10.2 software. The resulted map was classified into five classes of $<500,500$ $1000,1000-2000,2000-3000$ and $>3000 \mathrm{~m}$ that are shown in figure $4(\mathrm{~b})$.

\subsubsection{Topographic Wetness Index (TWI)}

TWI map determines the effect of topography on the amount of saturated levels to create runoffs and it is regarded as a useful index in investigating flood potential of watersheds. TWI is defined as equation (1):

$$
\mathrm{TWI}=\operatorname{Ln}\left(\frac{A_{S}}{\tan \beta}\right),
$$

where $A_{S}$ is the special area of watershed and $\beta$ is slope (in degrees) (figure 5a) (Rahmati et al. 2016b).

\subsubsection{Soil type}

This factor plays the most important role in creating surface runoff and subsurface flow. Lithological and pedologic features have a major effect on the amount of water permeability in soil or direct runoff and consequently balance in river flow or flooding of the watershed. Pedologic layer was prepared from soil texture map of Madarsoo

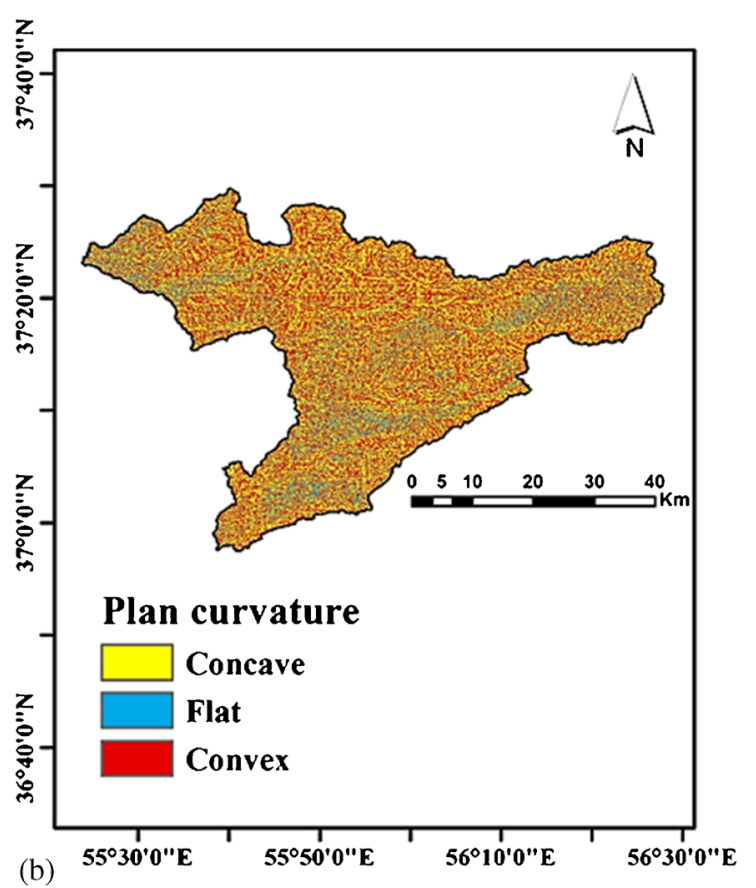

Figure 3. (a) Slope aspect map and (b) curvature of the earth in Madarsoo watershed. 


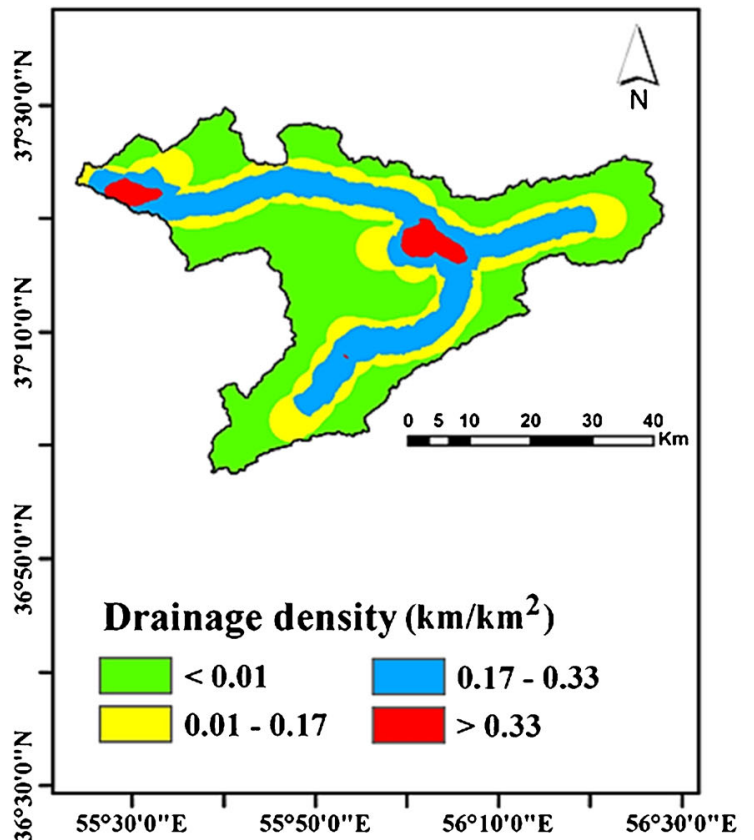

(a)

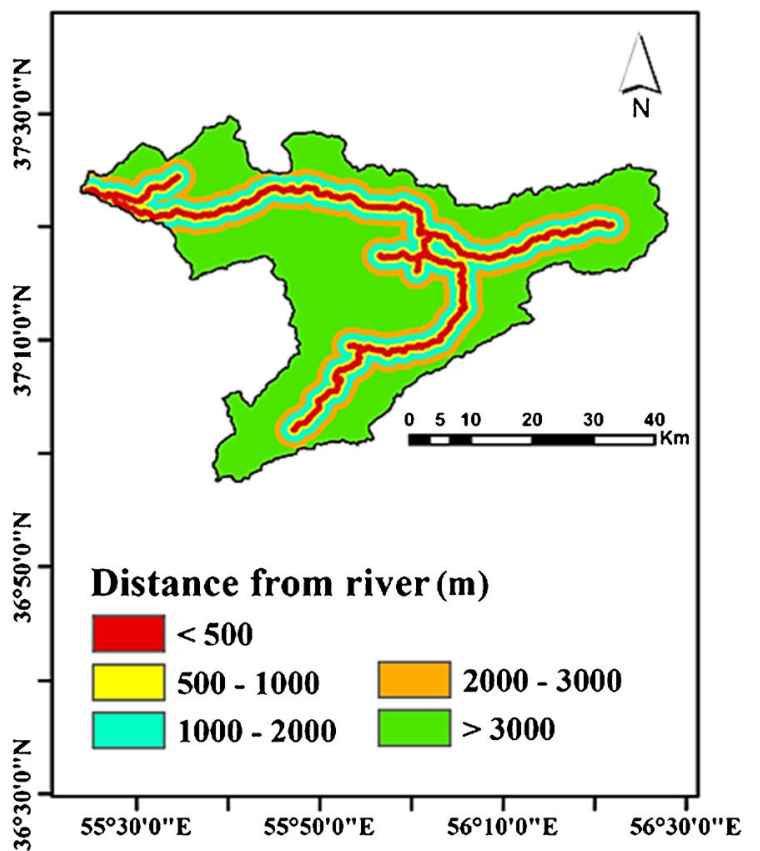

(b)

Figure 4. (a) Drainage density map and (b) distance from river in Madarsoo watershed.

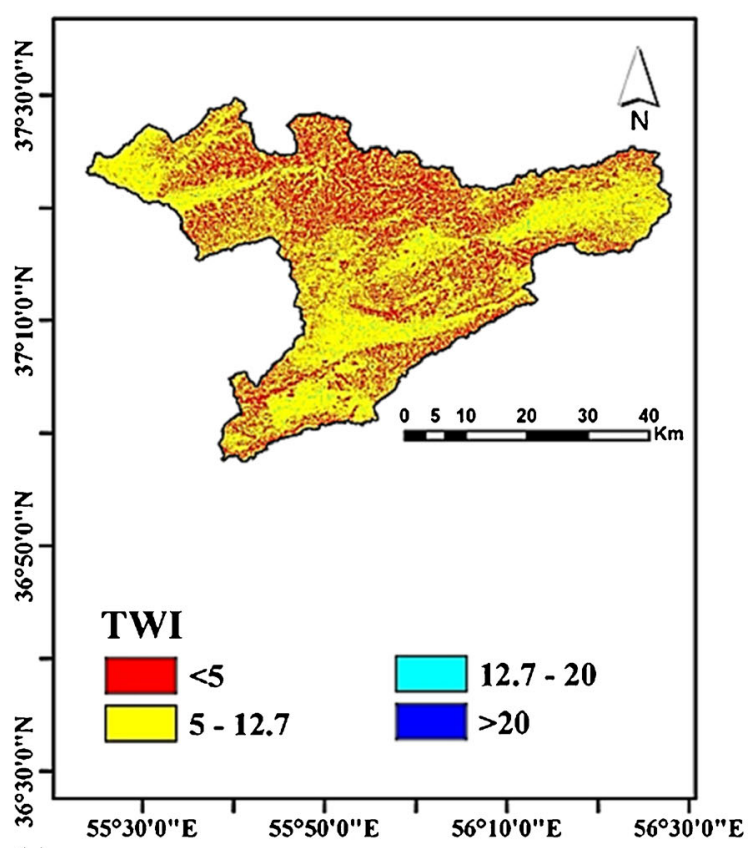

(a)

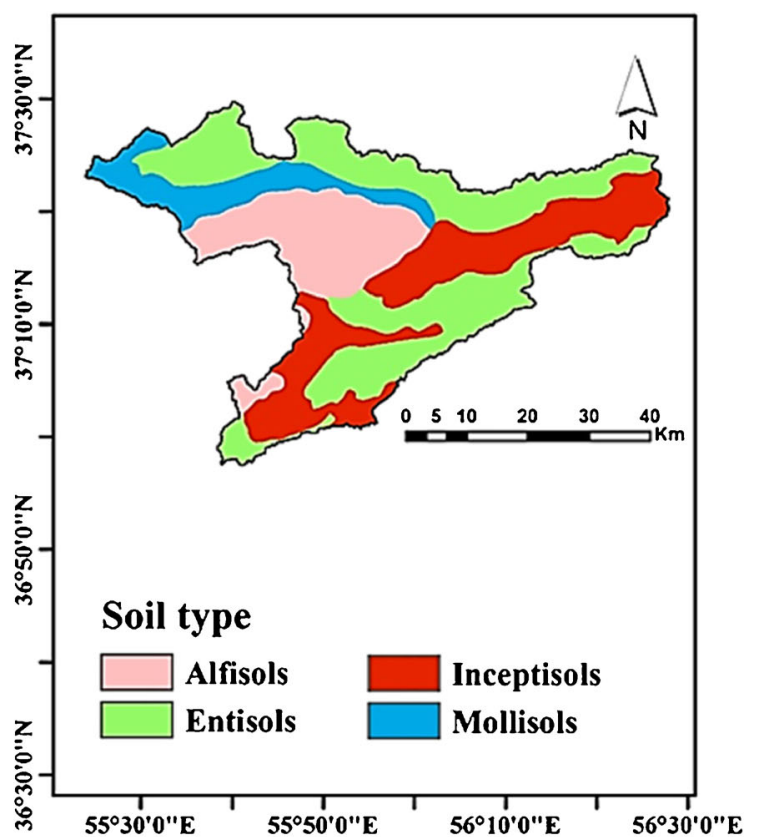

(b)

Figure 5. (a) Topographic wetness index map and (b) soil type in Madarsoo watershed.

watershed (1:100000 scale) presented by the Ministry of Agriculture (figure 5b).

\subsubsection{Lithology}

Because of having a direct influence on permeability power and surface runoff, lithology is an important factor in flooding of watershed basins. Lithological map of Madarsoo watershed was prepared and digitized using lithological 1:100000 scale maps from Geology Organization. Geology of the area was divided into age classes of Cretaceous, Devonian, Eocene, Jurassic, Miocene, Proterozoic, Cambrian, Silurian and Quaternary as shown in figure 6(a). 

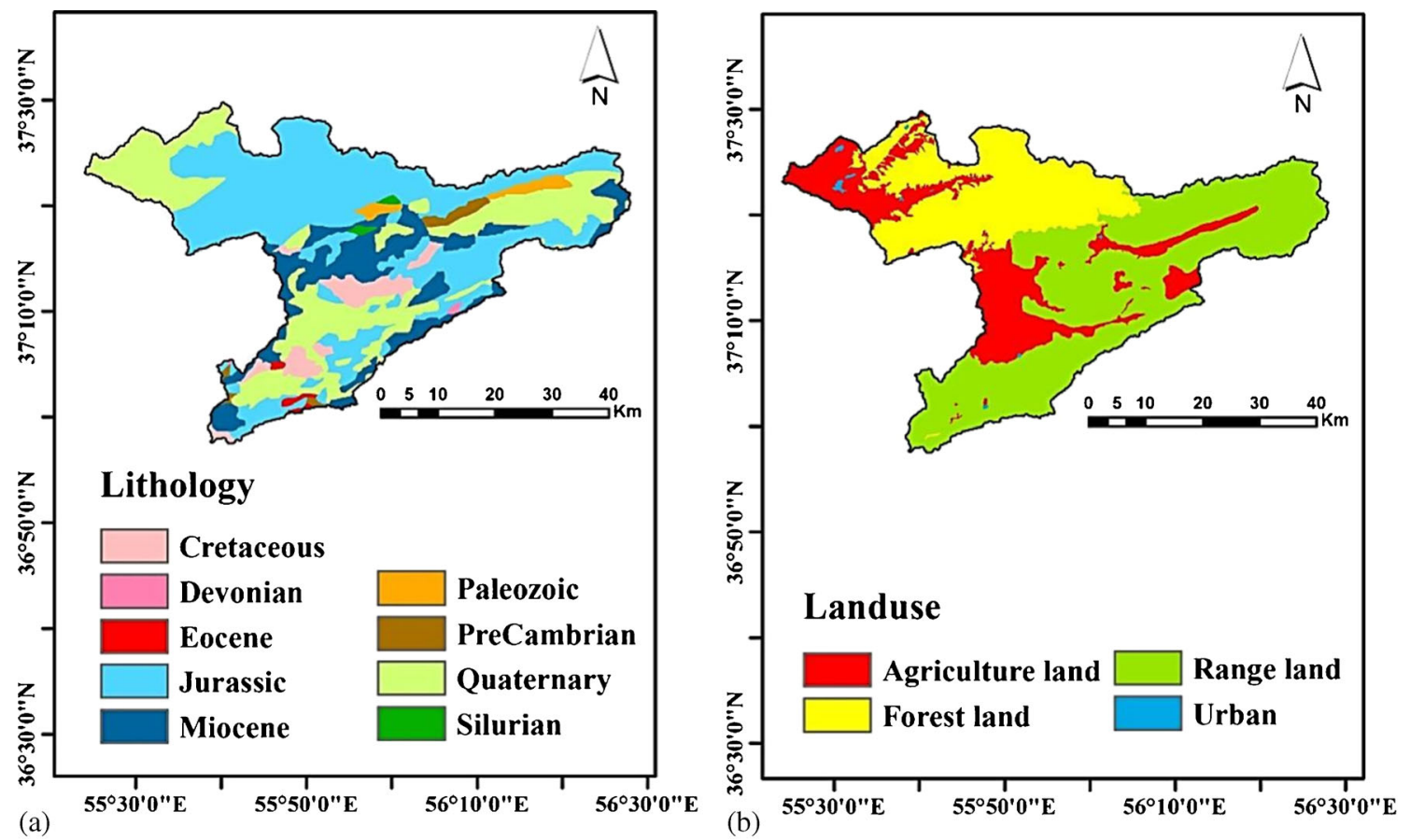

Figure 6. (a) Lithology and (b) land use map of Madarsoo watershed.

\subsubsection{Land use}

Land use is a major factor in creating surface runoff and flood potential of watersheds. The map of land use of Madarsoo watershed was prepared according to digitized land use maps from forest, rangeland and watershed management organizations. Land use map was divided into forests, rangelands, agricultural and residential lands as could be seen in figure $6(\mathrm{~b})$.

\subsection{Assessing the statistics of flood locations in recent decades}

In order to evaluate the potential of flooding, it is necessary to analyze the floods recorded in the area (Manandhar et al. 2010). Thus, based on the statistics of the basis of Golestan regional water company, a map containing the geographical location of the last 70 floods that occurred in Madarsoo watershed was prepared. This set of floods was randomly divided into two groups including a group of 49 flood locations (70\%) for training, and a group of 21 flood locations (30\%) for validation. The locations of flood events were provided as a raster network $(30 \times 30 \mathrm{~m})$ applicable in maximum entropy and frequency ratio models, then these locations were divided based on training and validation groups as shown in figure 1.

\section{Flood susceptibility modelling}

\subsection{Shannon's entropy index}

Entropy is a management approach employed in a system to prevent disorder, instability, disturbance and uncertainties available in that system (Pourghasemi et al. 2014). This theory was initially proposed by Stephan Boltzmann and it was finally presented quantitatively by Shannon (1948) (Pourghasemi et al. 2014). In fact, entropy states a way to estimate main factors among effective factors of an objective; in other words, it determines variables that are more influential in event occurrence. In general, equations (2-7) were employed to prioritize the affecting flood occurrence and to prepare its susceptibility map using the mentioned method (Bednarik et al. 2010; Constantin et al. 2011; Pourghasemi et al. 2012):

$$
\begin{gathered}
P_{i j}=\frac{b}{a}, \\
\left(P_{i j}\right)=\frac{P_{i j}}{\sum_{j=1}^{S_{j}} P_{i j}}, \\
H_{j}=-\sum_{i=1}^{S_{j}}\left(P_{i j}\right) \log _{2}\left(P_{i j}\right),
\end{gathered}
$$




$$
\begin{gathered}
H_{j \max }=\log _{2} S_{j}, \\
I_{j}=\frac{H_{j \max }-H_{j}}{H_{j \max }}, I=(0,1), \quad j=1, \ldots, n, \\
W_{j}=I_{j} P_{i j},
\end{gathered}
$$

where $a$ and $b$ are the domain and flood percentages, $\left(P_{i j}\right)$ is the probability density, $H_{j}$ and $H_{j \max }$ represent entropy values, $I_{j}$ is the information coefficient, $S_{j}$ is the number of classes and $W_{j}$ represents the resultant weight value for the factor as a whole (figure 7).

After determining the final weight of each factor and multiplying it in classes of that factor and $P_{i j}$ values related to each factor, weighted maps were added up and the final map of flood susceptibility was obtained.

Flood susceptibility index (FSI) was calculated using the following equations:

$$
\mathrm{FSI}=\sum_{i=1}^{n}\left(W_{j} P_{j}\right),
$$

$$
\begin{aligned}
\mathrm{FSI}= & \left(\mathrm{L}_{P_{j}} \times 0.22\right)+\left(\mathrm{LU}_{P_{j}} \times 0.38\right)+\left(\mathrm{DFR}_{P_{j}} \times 0.53\right) \\
& +\left(\mathrm{St}_{P_{j}} \times 0.9\right)+\left(\mathrm{S}_{P_{j}} \times 0.18\right)+\left(\mathrm{SA}_{P_{j}} \times 0.14\right) \\
& +\left(\mathrm{P}_{P_{j}} \times 0.03\right)+\left(\mathrm{TWI}_{P_{j}} \times 0.25\right) \\
& +\left(\mathrm{DD}_{P_{j}} \times 1.44\right)+\left(\mathrm{A}_{P_{j}} \times 0.94\right),
\end{aligned}
$$

where $W_{j}$ and $P_{j}$ are the final weight and the probability density for the $j$ th feature. L, LU, DFR, St, S, SA, P, TWI, DD, and A are lithology, land use, distance from river, soil texture, slope, slope aspect, plan curvature, topographic wetness index, drainage density, and altitude, respectively.

The resulting map of the layers is classified as Quantile and this classification map would be the final Shannon's entropy model (Pourghasemi et al. 2012; Ozdemir and Altural 2013; Pourghasemi et al. 2013a, b, c, d; Regmi et al. 2013; Zare' et al. 2013).

\subsection{Accuracy evaluation of flood forecasting map}

To evaluate the accuracy of flood potential forecasting map, 21 flood events related to last periods were employed that were not entered Shannon's entropy model to forecast flood potential. Figure 1

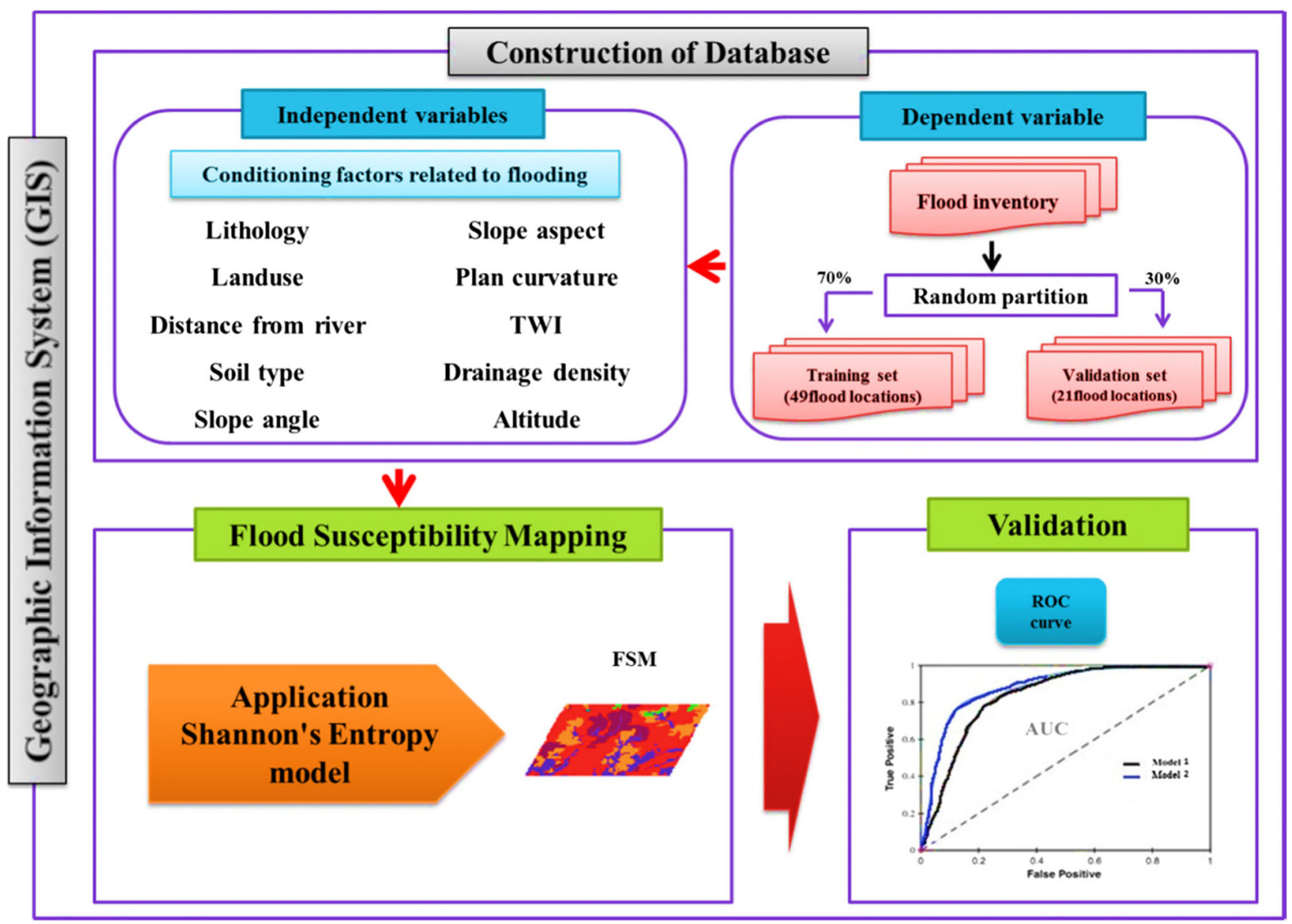

Figure 7. Flowchart showing the methodology adopted in this study. 
Table 1. Relationship between flood location, effective factors and determining their effects using Shannon's entropy index.

\begin{tabular}{|c|c|c|c|c|c|c|c|c|c|}
\hline Factor & Class & $\begin{array}{c}\text { Number of pixels } \\
\text { in basin }\end{array}$ & $\begin{array}{l}\text { Number } \\
\text { of floods }\end{array}$ & $P_{i j}$ & $\left(P_{i j}\right)$ & $H_{i j}$ & $H_{j \max }$ & $I_{j}$ & $W_{j}$ \\
\hline \multirow[t]{9}{*}{ Lithology } & Cretaceous & 130634 & 0 & 0 & 0 & \multirow[t]{9}{*}{1.24} & \multirow[t]{9}{*}{3.17} & \multirow[t]{9}{*}{0.61} & \multirow[t]{9}{*}{0.22} \\
\hline & Devonian & 4162 & 0 & 0 & 0 & & & & \\
\hline & Eocene & 13377 & 0 & 0 & 0 & & & & \\
\hline & Jurassic & 1185498 & 15 & 0.66 & 0.21 & & & & \\
\hline & Miocene & 384916 & 3 & 0.41 & 0.13 & & & & \\
\hline & Proterozoic & 44221 & 0 & 0 & 0 & & & & \\
\hline & Precambrian & 33612 & 0 & 0 & 0 & & & & \\
\hline & Quaternary & 759585 & 31 & 2.14 & 0.67 & & & & \\
\hline & Silurian & 10961 & 0 & 0 & 0 & & & & \\
\hline \multirow[t]{4}{*}{ Land use } & Agricultural land & 569019 & 28 & 2.58 & 0.68 & \multirow[t]{4}{*}{1.20} & \multirow[t]{4}{*}{2} & \multirow[t]{4}{*}{0.40} & \multirow[t]{4}{*}{0.38} \\
\hline & Forests & 707397 & 10 & 0.74 & 0.2 & & & & \\
\hline & Pasture land & 1282210 & 11 & 0.45 & 0.12 & & & & \\
\hline & Urban areas & 8340 & 0 & 0 & 0 & & & & \\
\hline \multirow[t]{5}{*}{ Distance from river $(\mathrm{m})$} & $<500$ & 216190 & 4 & 0.97 & 0.10 & \multirow[t]{5}{*}{1.66} & \multirow[t]{5}{*}{2.32} & \multirow[t]{5}{*}{0.29} & \multirow[t]{5}{*}{0.53} \\
\hline & $500-1000$ & 197138 & 14 & 3.72 & 0.40 & & & & \\
\hline & $1000-2000$ & 355363 & 27 & 3.98 & 0.43 & & & & \\
\hline & $2000-3000$ & 329857 & 4 & 0.64 & 0.07 & & & & \\
\hline & $>3000$ & 1468418 & 0 & 0 & 0 & & & & \\
\hline \multirow[t]{4}{*}{ Soil type } & Alfisols & 516267 & 2 & 0.20 & 0.03 & \multirow[t]{4}{*}{0.94} & \multirow[t]{4}{*}{2} & 0.53 & 0.90 \\
\hline & Entisols & 1080624 & 10 & 0.48 & 0.07 & & & & \\
\hline & Inceptisols & 688404 & 7 & 0.53 & 0.08 & & & & \\
\hline & Malisols & 281671 & 30 & 5.58 & 0.82 & & & & \\
\hline Slope angle (in degree) & $0-13.93$ & 1763692 & 35 & 1.04 & 0.42 & 1.46 & 2.32 & 0.37 & 0.18 \\
\hline & $13.93-27.85$ & 646449 & 13 & 1.05 & 0.43 & & & & \\
\hline & $27.85-41.78$ & 138807 & 1 & 0.38 & 0.15 & & & & \\
\hline & $41.78-55.72$ & 17097 & 0 & 0 & 0 & & & & \\
\hline & $55.72-69.7$ & 921 & 0 & 0 & 0 & & & & \\
\hline Slope aspect & Flat & 17179 & 1 & 3.05 & 0.29 & 2.78 & 3.17 & 0.12 & 0.14 \\
\hline & North & 418558 & 8 & 0 & 0.09 & & & & \\
\hline & North-east & 265949 & 3 & 0.59 & 0.06 & & & & \\
\hline & East & 235565 & 0 & 0 & 0 & & & & \\
\hline & South-east & 300124 & 4 & 0.70 & 0.06 & & & & \\
\hline & South & 397116 & 12 & 1.58 & 0.15 & & & & \\
\hline & South-west & 281170 & 6 & 1.12 & 0.10 & & & & \\
\hline & West & 284575 & 10 & 1.84 & 0.20 & & & & \\
\hline & North-west & 366730 & 5 & 0.71 & 0.07 & & & & \\
\hline Plan curvature & Concave & 1116224 & 27 & 1.27 & 0.41 & 1.54 & 1.58 & 0.03 & 0.03 \\
\hline & Flat & 363300 & 8 & 1.15 & 0.37 & & & & \\
\hline & Convex & 1087442 & 14 & 0.67 & 0.22 & & & & \\
\hline TWI & $<5$ & 861256 & 12 & 0.73 & 0.38 & 0.96 & 2 & 0.52 & 0.25 \\
\hline & $5-12.7$ & 1662190 & 37 & 1.17 & 0.61 & & & & \\
\hline & $12.7-20$ & 41763 & 0 & 0 & 0 & & & & \\
\hline & $>20$ & 1757 & 0 & 0 & 0 & & & & \\
\hline Drainage density $\left(\mathrm{km} / \mathrm{km}^{2}\right)$ & $0.01<$ & 1338984 & 0 & 0 & 0 & 1.01 & 2 & 0.50 & 1.44 \\
\hline & $0.01-0.17$ & 549363 & 5 & 0.48 & 0.04 & & & & \\
\hline & $0.17-0.33$ & 598433 & 31 & 2.71 & 0.23 & & & & \\
\hline & $>0.33$ & 80186 & 13 & 8.49 & 0.73 & & & & \\
\hline Altitude (m) & $<500$ & 276460 & 32 & 6.06 & 0.82 & 0.84 & 2.32 & 0.64 & 0.94 \\
\hline & $500-1000$ & 272046 & 4 & 0.77 & 0.10 & & & & \\
\hline & $1000-1500$ & 1305610 & 13 & 0.52 & 0.07 & & & & \\
\hline & $1500-2000$ & 666306 & 0 & 0 & 0 & & & & \\
\hline & $>2000$ & 46544 & 0 & 0 & 0 & & & & \\
\hline
\end{tabular}


shows the location of these floods. Forecasting accuracy of flood potential in Madarsoo watershed was calculated using ROC index. ROC curve is a graphical representation of equilibrium between the negative and positive rate of error for each possible value of fitness (Pourghasemi et al. 2014). If the index value (or area under the curve) equals 1 , it shows complete fitness of the model and if it equals 0.5, it represents the lack of fitness of model (Zare' Garizi et al. 2012). Qualitative-quantitative correlation of the area under curve and evaluation of estimation is as follows: $0.9-1$ : perfect; $0.8-0.9$ : very good; 0.7-0.8: good; 0.6-0.7: medium and 0.5-0.6: weak (Pradhan and Lee 2010; Regmi et al. 2010; Pourghasemi et al. 2012, 2014).

\section{Results and discussion}

In this study, first, entropy values were calculated for effective parameters in the study area using relations presented in Shannon's entropy model, as could be seen in table 1 . Results of investigating factor of elevation map indicate that the highest rate of flood has occurred in elevations that are lower than $500 \mathrm{~m}$, i.e., in higher altitudes and mountainous areas, flood events are less. Gradient controls surface runoff permeability and water flow speed. In areas with medium slope, runoff flow is slow and water has much time to penetrate. The less the gradient, the more is the possibility of flooding and flood events (Rahmati et al. 2016c).
Aspect impacts delay in thawing resulted from temperature difference, soil moisture, evaporation, respiration and vegetation (Rahmati et al. 2016c). After investigating the aspect of Madarsoo watershed, it could be stated that in lands with no aspect (flat), the highest number of flood events are observed; south, north, west, north-west and southwest aspects are of medium flood rate and the lowest flood prevalence could be observed in north-east aspect. Land curvature index verifies that concave lands experience the highest flood event. Drainage density of $>0.33$ with highest $P_{i j}$ value demonstrates that this class is strongly related to flood events. Distance from the river demonstrates that the highest flood event is expected up to $2000 \mathrm{~m}$ away from the river; i.e., there is a greater flood possibility in this distance from the river compared to other areas and as the distance from river increases, the possibility of flood event decreases significantly. TWI parameter defines the effect of topography in producing runoff assuming steady and homogenous soil conditions. Evaluating this index demonstrates that in $0-12.7$ class, $P_{i j}$ value is the highest. Mollisols have experienced the highest flood rate and features of this soil depend on the soil type of the study area. The factor of geology demonstrates that the highest flood rate has been observed in Quaternary formations, the cause of which is related to marl and conglomerate in this formation. Marl is of lowest permeability, highest runoff and highest erosion. The factor of land use represents that agricultural lands experience

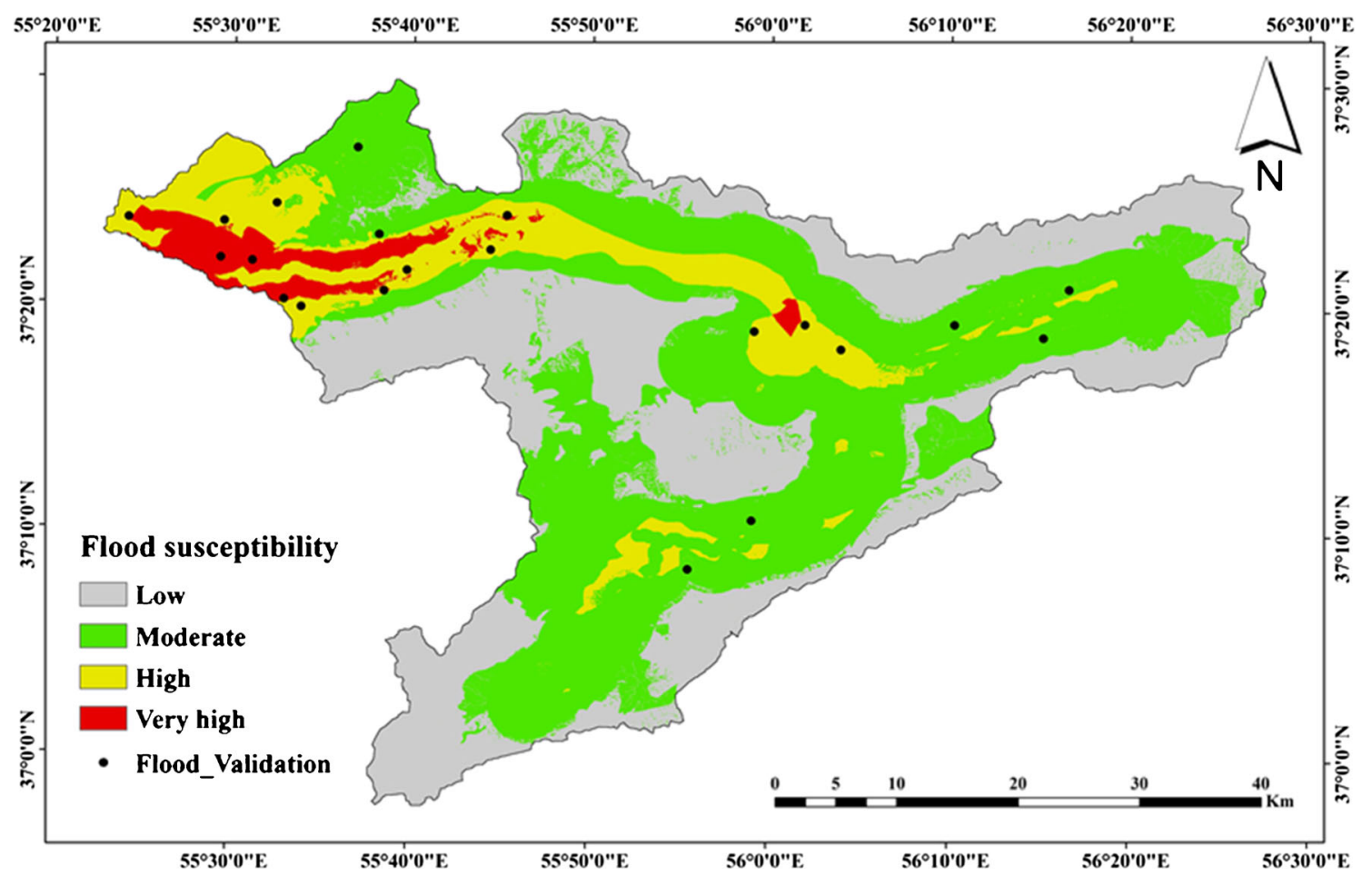

Figure 8. Flood potential forecasting map of Madarsoo watershed using Shannon's entropy model. 


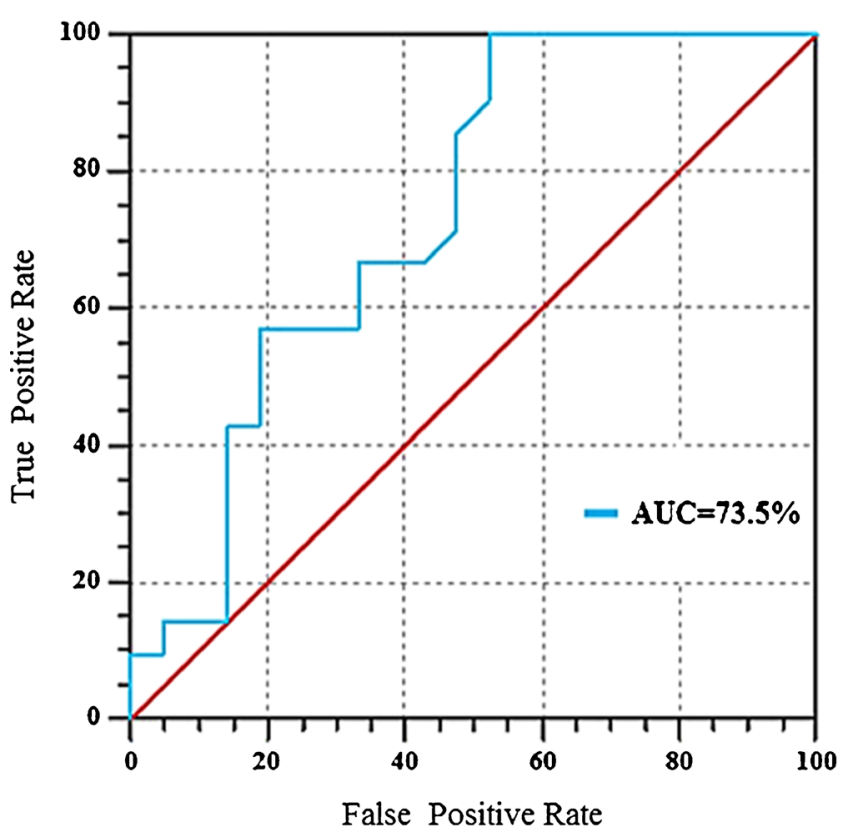

Figure 9. ROC curve of flood potential forecasting map based on Shannon's entropy model in Madarsoo watershed.

the highest flood event, which happens because of impermeability of agricultural lands (plowing agricultural lands prevents water from permeating into the soil), increase in runoff and therefore increases in flood severity.

$W_{j}$ results demonstrate that the highest weight is assigned to factors of drainage density, elevation, lithology and distance from the river (1.44, 094, 0.90 , and 0.53$)$, while the lowest is assigned to the factor of curvature of the earth (0.03).

According to the results obtained from analyses, flood potential forecasting map of Madarsoo watershed was provided using Shannon's entropy model based on 10 factors affecting flood occurrence that could be seen in figure 8 .

As stated before, ROC curve was employed to evaluate the model. This curve is the most effective method in presenting characteristic determination, possible recognition and forecasting systems that estimates model accuracy quantitatively. According to the results of ROC curve, the area under curve value of the study area was $73.5 \%$ with standard deviation of 0.079 that represents a good evaluation of Shannon's entropy model (figure 9).

\section{Conclusion}

Preparing flood susceptibility map provides the background for recognizing factors affecting flood event, its occurrence, planning for risk management and risk prevention methods. In this study, flood-prone areas were recognized using Shannon's entropy model. In the first stage, the location map of flood events was provided according to data from
Golestan Regional Water Company. Then, 10 information layers of factors affecting flood occurrence (altitude, slope angle, slope aspect, plan curvature, distance from the river, soil type, drainage density, topographic wetness index, lithology and land use) were prepared in ArcGIS 10.2 software. In the third stage, flood susceptibility map was provided using Shannon's entropy theory and finally, ROC curve was prepared using validation data and then it was employed to evaluate the accuracy of maps. Results of validation demonstrate that Shannon's entropy is of good performance in recognizing flood susceptible areas in Madarsoo watershed. It could be suggested that scientific information obtained from this study could be employed by the government, planners and engineers to implement control projects in order to reduce flood damage in future.

\section{Acknowledgements}

This research was supported by Department of Watershed Management Engineering, Lorestan University. We thank our colleagues from Lorestan University who provided insight and expertise that greatly assisted the research.

\section{References}

Abdideh M, Qorashi M, Rangzan M and Aryan M 2011 Assessment of relative active tectonics using morphometric analysis, case study of Dez river (southwestern Iran); Scientific Quart. J. Geosci. 80 33-46.

Aniya M 1985 Landslide-susceptibility mapping in the Amahata river basin, Japan; ANN Assoc. Am. Geogr. 75 102114.

Bednarik M, Magulova B, Matys M and Marschalko M 2010 Landslide susceptibility assessment of the KralovanyLiptovsky Mikulaš railway case study; Phys. Chem. Earth 35 162-171.

Campolo M, Soldati A and Andreussi P 2003 Artificial neural network approach to flood forecasting in the River Arno; Hydrol. Sci. J. 48 381-398.

Constantin M, Bednarik M, Jurchescu M C and Vlaicu M 2011 Landslide susceptibility bivariate statistical analysis and the index of entropy in the Sibiciu Basin (Romania); Environ. Earth Sci. 63 397-406.

Hosseini M and Matlabifar F 2008 Study and investigation of flood management and solutions to reduce flood damages, Sepehr (Geographical Organization), 16th year; 63.

Hosseinpour A and Abbaspour R A 2014 Optimization of landslide forecasting results using Shannon's entropy theory; Knowl. Hazards 2 253-268.

Jaafari A, Najafi A, Pourghasemi H R, Rezaeian J and Sattarian A 2013 GIS-based frequency ratio and index of entropy models for landslide susceptibility assessment in the Caspian forest, northern Iran; Int. J. Environ. Sci. Technol., doi: 10.1007/s13762-013-0464-0.

Kawachi T, Maruyama T and Singh V P 2001 Rainfall entropy for delineation of water resources zones in Japan; J. Hydrol. 246(1) 36-44.

Kia M B, Pirasteh S, Pradhan B, Mahmud A R, Sulaiman W N A and Moradi A 2012 An artificial neural network model for flood simulation using GIS: Johor River Basin, Malaysia; Environ. Earth Sci. 67 251-264. 
Lee M J, Kang Je and Jeon S 2012 Application of frequency ratio model and validation for predictive flooded area susceptibility mapping using GIS. IGARSS; IEEE Int., doi: 10.1109/IGARSS.2012.6351414.

Li C, Singh V P and Mishra A K 2012 Entropy theorybased criterion for hydrometric network evaluation and design: Maximum information minimum redundancy; Water Resour. Res. 48(5).

Liu Y and De Smedt F 2005 Flood modeling for complex terrain using GIS and remote sensed information; Water Resour. Manag. 19 605-624.

Manandhar B, Balla M K, Awal R and Pradhan B M 2010. Floodplain analysis and risk assessment of lothar khola (stream); MSc Thesis, Tribhuvan University, Phokara, Nepal, 64p.

Mishra A K and Coulibaly P 2010 Hydrometric network evaluation for Canadian watersheds; J. Hydrol. 380(3) 420-437.

Mishra A K and Coulibaly P 2014 Variability in Canadian seasonal streamflow information and its implication for hydrometric network design; J. Hydrol. Eng. 19(8) 05014003.

Mishra A K, Özger M and Singh V P 2009 An entropybased investigation into the variability of precipitation; J. Hydrol. 370(1) 139-154.

Naghibi S A, Pourghasemi H R, Pourtaghie Z S and Rezaei A 2014 Groundwater qanat potential mapping using frequency ratio and Shannon's entropy models in the Moghan watershed, Iran; Earth Sci. Inform. 8(1) 171-186.

Ozdemir A and Altural T 2013 A comparative study of frequency ratio, weights of evidence and logistic regression methods for landslide susceptibility mapping: Sultan Mountains, SW Turkey; J. Asian Earth Sci. 64 180197.

Pourghasemi H R, Mohammady M and Pradhan B 2012 Landslide susceptibility mapping using index of entropy and conditional probability models in GIS: Safarood Basin, Iran; Catena 97 71-84.

Pourghasemi H R, Pradhan B, Gokceoglu C and Moezzi K D 2013a A comparative assessment of prediction capabilities of Dempster-Shafer and weights-of-evidence models in landslide susceptibility mapping using GIS; Geomat. Nat. Hazards 4 93-118.

Pourghasemi H R, Pradhan B, Gokceoglu C, Mohammadi M and Moradi H R 2013b Application of weights-of-evidence and certainty factor models and their comparison in landslide susceptibility mapping at Haraz watershed, Iran; Arab. J. Sci. Eng. 6 2351-2365.

Pourghasemi H R, Jirandeh A G, Pradhan B, Xu C and Gokceoglu C 2013c Landslide susceptibility mapping using support vector machine and GIS at the Golestan Province, Iran; J. Earth Syst. Sci. 122 349-369.

Pourghasemi H R, Moradi H R and Aghda S M F 2013d Landslide susceptibility mapping by binary logistic regression, analytical hierarchy process, and statistical index models and assessment of their performances; Nat. Hazards 69 749-779.

Pourghasemi H R, Moradi H R and Fatemi Aghda S M 2014 Prioritizing factors affecting landslide and zonation of its susceptibility using Shannon's entropy index; Soil Water Sci. 70 181-191.

Pradhan B and Lee S 2010 Landslide susceptibility assessment and factor effect analysis: Back propagation artificial neural networks and their comparison with frequency ratio and bivariate logistic regression modelling; Environ. Model. Softw. 25 747-759.

Rahmati O, Haghizadeh A and Stefanidis S 2016a Assessing the accuracy of GIS-based analytical hierarchy process for watershed prioritization; Gorganrood River Basin, Iran; Water Resour. Manag. 30(3) 1131-1150.

Rahmati O, Haghizadeh A, Pourghasemi H R and Noormohamadi F 2016b Gully erosion susceptibility mapping: The role of GIS-based bivariate statistical models and their comparison; Nat. Hazards 82(2) 1231-1258.

Rahmati O, Pourghasemi H R and Zeinivand H 2016c Flood susceptibility mapping using frequency ratio and weights-of-evidence models in the Golastan Province, Iran; Geocarto Int. 31(1) 42-70.

Rajsekhar D, Mishra A K and Singh V P 2012 Regionalization of drought characteristics using an entropy approach; J. Hydrol. Eng. 18(7) 870-887.

Regmi A D, Devkota K C, Yoshida K, Pradhan B, Pourghasemi H R, Kumamoto T and Akgun A 2013 Application of frequency ratio, statistical index, and weights-of-evidence models and their comparison in landslide susceptibility mapping in central Nepal Himalaya; Arab. J. Sci. Eng. 7 725-742.

Regmi N R, Giardino J R and Vitek J D 2010 Modeling susceptibility to landslides using the weight of evidence approach: Western Colorado, USA; Geomorphol. 115 $172-187$.

Sanyal J and Lu X X 2004 Application of remote sensing in flood management with special reference to monsoon Asia: A review; Nat. Hazards 33 283-301.

Shafapour Tehrani M, Lee M J, Pradhan B and Neamah Jebur M 2013 Spatial prediction of flood susceptible areas using rule based decision tree (DT) and a novel ensemble bivariate and multivariate statistical models in GIS; J. Hydrol. 504 69-79.

Shafapour Tehrani M, Lee M J, Pradhan B, Neamah Jebur M and Lee S 2014 Flood susceptibility mapping using integrated bivariate and multivariate statistical models; J. Hydrol. 512 332-343.

Singh V P 1997 The use of entropy in hydrology and water resources; Hydrol. Process. 11 587-626.

Skilodimou H, Livaditis G, Bathrellos G and Verikiouâ Papaspiridakou E 2003 Investigating the flooding events of the urban regions of Glyfada and Voula, Attica, Greece: A contribution to urban geomorphology; Geogr. Ann. A 85 197-204.

Tahmassebipoor N, Rahmati O, Noormohamadi F and Lee S 2016 Spatial analysis of groundwater potential using weights-of-evidence and evidential belief function models and remote sensing; Arab. J. Geosci. 9(1) 1-18.

Zare' Garizi A, Brady Sheikh V, Saad Eddin A and Salman Mahini A 2012 Applications logistic regression modeling to change the spatial pattern of vegetation (Case study: Watershed Chehelchay, Golestan Province); Geogr. Space 37 55-68.

Zare' M, Pourghasemi H R, Vafakhah M and Pradhan B 2013 Landslide susceptibility mapping at Vaz Watershed (Iran) using an artificial neural network model: A comparison between multilayer perceptron (MLP) and radial basic function (RBF) algorithms; Arab. J. Sci. Eng. 6 2873-2888. 